\title{
Genetic diversity studies on seven Egyptian wheat (Triticum aestivum L) cultivars using Scot and ISSR polymorphism markers
}

\begin{abstract}
Nosair H.R.
Department of Botany, Faculty of Science, Ain Shams university, Cairo, Egypt. Email: hrnosair@yahoo.com

\section{Abstract}

Assessment of genetic diversity of crops by using informative molecular markers is important for their genetic improvement and conservation. Genetic diversity and relationships among seven Egyptian cultivars of wheat (Triticum aestivum L) (Masr1, Swiss2, Swiss4, Giza7, Giza9, Giza10 and Sakha94) were analyzed using SCoT and ISSR markers. A total of 7 SCoT and 7 ISSR primers were used to estimate genetic polymorphism among seven wheat cultivars (Masr1, Swiss2, Swiss4, Giza7, Gisa9, Giza10 and Sakha94). DNA extraction was done using Thermo Kit according to its manufacturer's instructions followed by amplifications with ISSR and SCoT and agarose gel electrophoresis. Based on UPGMA both ISSR and SCoT markers resolved cultivars into dendrogram with three major cluster. The reproducible bands were scored for analyses polymorphic information content (PIC), Resolving power (RP) and Marker index (MI). Comparatively, two markers were effective. The average polymorphic information content (PIC), Resolving power (RP)and Marker index (MI) of SCoT were reflected relatively higher than those of ISSR. According to the present results, SCoT markers proved more informative in studying genetic diversity among seven wheat cultivars. The results demonstrated that SCoT and ISSR markers are useful for genetic diversity analysis of wheat cultivars. This information is useful for utilization in plant breeding programs.
\end{abstract}

Keywords: Inter-Simple Sequence Repeats (ISSR), Start Codon Targeted (SCoT) marker, Polymorphic Information Content (PIC), Resolving Power (RP) and Marker Index (MI).

\section{Introduction}

Cereal grains have been the principal constituent of the human diet for hundreds of centuries and have affected in human civilization (Awika, 2011) Wheat, the world's major cereal crop, accounted for constituents $31 \%$ of global cereal consumption in 1999 (FAO, 2002). Wheat represents around $37 \%$ of caloric utilization in the Middle East and North Africa region. The region is communally a net important of 58 million metric tons of cereal, making it the largest net importer region in the world (Wright and Cafiero, 2010)

Concerning Egypt, Bread wheat (Triticum aestivum L.) is one of the most important crops and its local production is about 8 million tons, conversely; it covers less than $60 \%$ of local consumption (FAO., 2009). Therefore, wheat productivity must be enhanced in Egypt, (Abdel-Razek, 2013). Essential objective of Egyptian Government is filling gap between wheat production and consumption (Abd El-Mohsen et al.,2012). consequently, using of plant breeding program is very important for production of promising wheat harvest. Cultivation of crops with different genetic background is an effective strategy for maintenance and to reduce genetic weakness in crop enhancement (Smale et al., 2002; Mardi et al., 2011). Crops tolerance to biotic and abiotic stress needs strong genetic diversity. 


\section{Genetic diversity studies on seven Egyptian wheat}

(Talebi et al., 2012). Therefore, knowledge of the genetic diversity in crops is important in crop breeding programs (Soleimani et al., 2002)

Molecular markers are useful accompaniments to morphological and molecular characterization because they are abundant independent of environmental effects and allow cultivar identification in the early steps of development (Chen et al., 2009; Yu and Pauls 1993., Biswas et al., 2014 and Cabo et al., 2014). Recently, Collard and Mackill (2009) described a simple and novel DNA marker technique Start Codon Targeted (SCoT) Polymorphism. This marker technique uses 18-mer single primer in PCR and an annealing temperature of at 50C, and PCR products are resolved using standard agarose gel electrophoresis. The primers are very easy to design based on the preserved region surrounding the translation initiation codon, ATG (Joshi et al., 1997; Milbourne et al., 1997; Sawant et al., 1999) without the requisites of genomic sequence information. Inter-simple sequence repeats (ISSR) marker is identified by means of repeaters' anchored primers that are amplified between SSRs and has also been used to analyses the genetic diversity among different species of plants. Furthermore, this technique, due to high repeatability and polymorphism, as well as highly informative, is suitable for assessing genetic diversity in different crops (Bornet et al., 2001, Moradkhani et al., 2012 and 2015, Al-kordy et al., 2013 and Abdel-Lateif et al., 2018)). Thus, the main goal of the present study was to determine the genetic variability in the used 7 cultivars (Masr1, Swiss2, Swiss4, Giza7, Giza9, Giza10 and Sakha94) of Egyptian wheat using SCoT and ISSR markers.

\section{Material \& Methods:}

Seven Egyptian cultivars of wheat grains were obtained from Agricultural Genetic Engineering Research Institute (AGERI) and cultivated in the garden of botany department of science collage, Ain Shams University. The seedling leaves were used for DNA extraction.

\section{Genomic DNA extraction:}

The genomic DNA was extracted from the seedling leaves by (Thermo Scientific Gene JET Plant Mini Kit) Agarose gel electrophoresis definite that the DNA was of high molecular weight with no degradation.

\section{SCoT\& ISSR analysis:}

Seven SCoT \& ISSR primers were used in this study (Tables $1 \& 2$ ). The PCR amplification was performed in a $25 \mu \mathrm{l}$ reaction volume containing about $3 \mu \mathrm{l}$ (10 ng/ $\mu \mathrm{l})$ genomic DNA, $1 \mu \mathrm{l}$ primer, 1.5 mMMgCl2, $0.2 \mathrm{mM}$ of each dNTP, $0.4 \mu \mathrm{M}$ of a primer; $50 \mathrm{ng}$ genomic DNA and 2U of Taq DNA polymerase. The thermal cycler was programmed with an initial step of $5 \mathrm{~min}$ at $94^{\circ} \mathrm{C}$; the amplification reaction was carried out using 40 cycles of 40 seconds at $94^{\circ} \mathrm{C}$, an annealing step of $1 \mathrm{~min}$ at a specific annealing temperature for each primer (Tables1 \& 2) and an elongation step of $1 \mathrm{~min}$ at $72^{\circ} \mathrm{C}$; and finally, a 7 min extension at $72^{\circ}$ C. All PCR amplification products were separated on $1.5 \%$ agarose gel in TBA, stained with ethidium-bromide.

\section{Data analysis:}

In order to measure the informativeness of the markers to differentiate between genotypes, polymorphism information content (PIC), marker index (MI) and resolving power (RP) were calculated. PIC was calculated according to the formula of (Anderson et al., 1993), MI was determined according to (Varshney et al., 2007). The RP of each primer was calculated according to (Prevost and Wilkinson, 1999). 


\section{Nosair H.R.}

\section{Results}

\section{SCoT analysis:}

SCoT analysis with seven primers of 7 Egyptian cultivars of bread wheat were done as shown in (Fig. 4). The number of total bands, the polymorphism, and \% of polymorphism was presented in (Table 1). The total number of bands was 96 fragments and the number of bands by each primer varied from 7 to 28 fragments. Scot46 amplified the highest number of bands (28 bands), while Scot28 primer produced the lowest number of bands (7 bands). All the primers used were found to produce polymorphic bands. The percent of polymorphism revealed by the different primers ranged from $100 \%$ for Scot $(7,14$, 24, 28, 35 \& 46) primer to $90 \%$ for Scot11 primer. PIC values ranged from 0.40 (Scot24) to 0.62 (SCoT.35), with an average value of 0.52 per primer (Table 1 ). The of Resolving power of SCoT marker is 42.5.MI of SCoT primer were at the (Table, 1 )

\section{Cluster analysis:}

Based on UPGMA clustering algorithm generating from obtained SCoT database, the seven cultivars were grouped into 3 clusters (Fig. 1). Cluster I consisted of two clades the first contain the cultivar swiss 2 and the second divided to two subclades the cultivars swiss4 in the first and Giza7 in the second. Cluster II is divided into two clades the cultivar Giza9 is in the first and the second subgroup is divided into two subclades the cultivars Giza10 is in the first subclade and cultivars Sakha 94 is in the second. Cluster III contains only cultivars Masr1.

\section{ISSR analysis:}

ISSR analysis with seven primers of 7 Egyptian cultivars of bread wheat were done as shown in (Fig. 4). The number of total bands, the polymorphism, and \% of polymorphism was presented in Table 2 . The total number of bands was 54 and the number of bands by each primer varied from 5 to 16 . the highest number of bands (16 bands) is in ISSR5, while ISSR 2 \& 6 primer produced the lowest number of bands (5 bands) The polymorphism percentage revealed by the different primers ranged from $100 \%$ for ISSR1 \& 6 primer to 50\% for ISSR4 primer. PIC values ranged from 0.21 (ISSR2) to 0.71 (ISSR 1 \& 6), with an average value of 0.42 per primer (Table 2). The Resolving power (RP) of ISSR marker is 19.3. Marker index (MI) of ISSR primer were at table (2).

Table (1). Data of SCoT primers and the extent of polymorphism.

\begin{tabular}{clcccccccccc}
\hline $\begin{array}{c}\text { p. } \\
\text { no. }\end{array}$ & $\begin{array}{l}\text { Primer } \\
\text { ID. }\end{array}$ & Seq5 ------3 & ANT & M & Po & Un & TNB & P (\%) & PIC & RP & MI \\
\hline 1 & Scot7 & ACAATGGCTACCACTGAC & 54 & 0 & 9 & 8 & 16 & 100 & 0.48 & 3.44 & 7.68 \\
2 & Scot11 & ACAATGGCTACCACTACC & 54 & 1 & 5 & 4 & 10 & 90 & 0.43 & 3.22 & 3.87 \\
3 & Scot14 & ACCATGGCTACCAGCGCG & 60 & 0 & 7 & 7 & 14 & 100 & 0.48 & 4.34 & 5.32 \\
4 & Scot24 & CCATGGCTACCACCGCAG & 80 & 1 & 2 & 12 & 15 & 100 & 0.40 & 5.04 & 5.6 \\
5 & Scot28 & CAACAATGGCTACCACCA & 54 & 1 & 4 & 2 & 7 & 100 & 0.60 & 2.24 & 3.42 \\
6 & Scot35 & AACCATGGCTACCACCAC & 56 & 1 & 2 & 13 & 16 & 100 & 0.62 & 4.92 & 6.3 \\
7 & Scot46 & ACCATGGCTACCACCGCC & 60 & 0 & 4 & 16 & 28 & 100 & 0.52 & 3.22 & 8.4 \\
& & & 4 & 32 & 70 & 96 & 97.8 & & 42.5 & \\
& total & & & & & & & & 0.50 & & \\
\hline
\end{tabular}

(ANT) annealing temperature, (NMB) number of monomorphic bands, (NPB) number of polymorphic bands, (TNB) total number of bands, (NUB) number of unique bands unique band (PPB), percentage of polymorphic bands, (PIC) polymorphism information content, (RP) resolving power, (MI) marker index 


\section{Genetic diversity studies on seven Egyptian wheat}

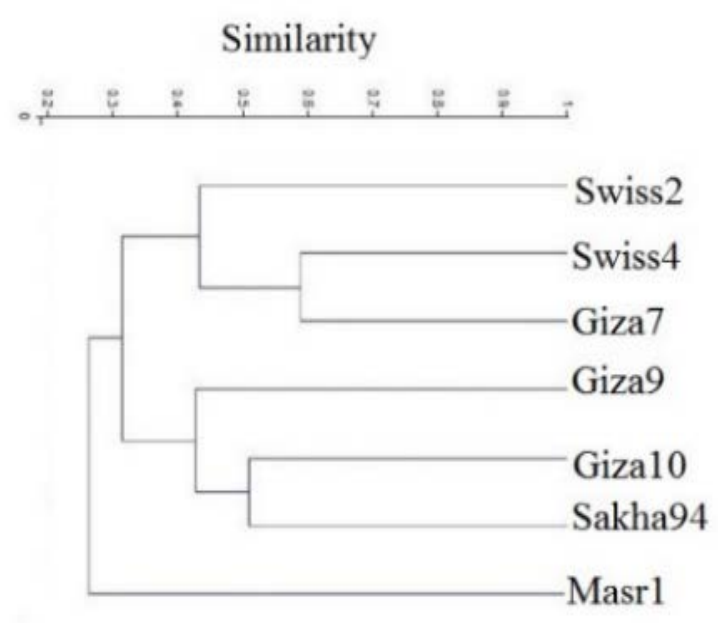

Fig.1. Dendrogram of 7 wheat cultivars resulting from the UPGMA cluster analysis based on Jaccard's similarity coefficients obtained from 7 SCoT marker.

\section{Cluster analysis:}

The seven cultivars were divided into three cluster. The first cluster contain Masr1 cultivar and the second were divided into three clades, the first clade were divided into two subgroups one subclade contains Swiss4 cultivar while swiss2 cultivar were found in

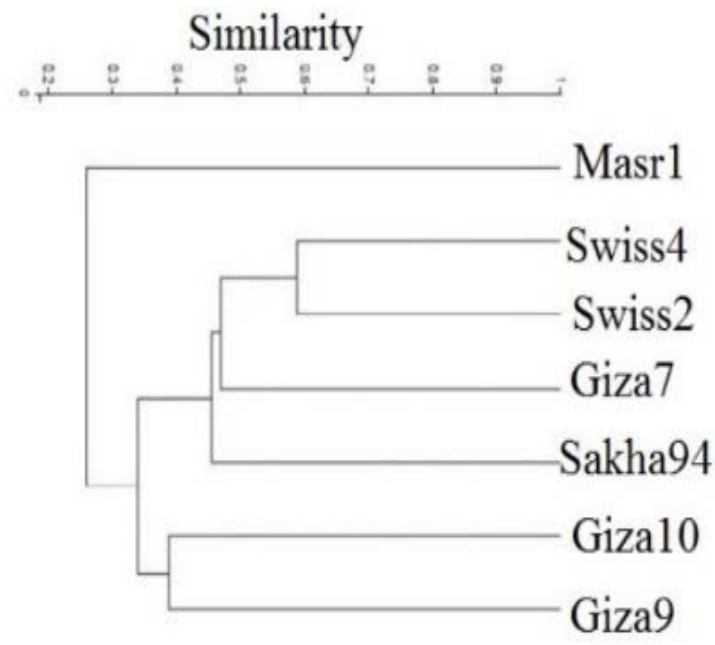

Fig. 2. Dendrogram of 7 wheat cultivars resulting from the UPGMA cluster analysis based on Jaccard's similarity coefficients obtained from ISSR marker

the second subgroup. The second clade contains only Giza7 cultivar and Sakha94 cultivar were found in clade three. The third cluster were divided into two clades, the first clade contains cultivar Giza10 while the second contains Giza9 cultivar.

Table (2). Data of ISSR primers and the extent of polymorphism.

\begin{tabular}{|c|c|c|c|c|c|c|c|c|c|c|c|}
\hline $\begin{array}{l}\text { p. } \\
\text { no. }\end{array}$ & $\begin{array}{l}\text { Primer } \\
\text { ID. }\end{array}$ & Seq5\-------3\ & ANT & NMB & NPB & NUB & TNB & РPB & PIC & $\mathrm{RP}$ & MI \\
\hline 1 & Issr1 & AGAGAGAGAGAGAGAGYC & 55 & 0 & 2 & 8 & 10 & 100 & 0.39 & 3.68 & 3.9 \\
\hline 2 & Issr2 & AGAGAGAGAGAGAGAGYG & 55 & 2 & 2 & 1 & 5 & 60 & 0.21 & 1.54 & 0.63 \\
\hline 3 & Issr3 & ACACACACACACACACYT & 53 & 1 & 1 & 4 & 6 & 83 & 0.71 & 1.54 & 3.55 \\
\hline 4 & Issr4 & ACACACACACACACACYG & 55 & 3 & 0 & 3 & 6 & 50 & 0.41 & 2.52 & 1.23 \\
\hline 5 & Issr6 & CGCGATAGATAGATAGATA & 52 & 0 & 7 & 9 & 16 & 100 & 0.22 & 5.5 & 3.3 \\
\hline 6 & Issr7 & GACGATAGATAGATAGATA & 50 & 1 & 2 & 2 & 5 & 80 & 0.53 & 2.28 & 2.65 \\
\hline \multirow[t]{3}{*}{7} & Issr9 & GATAGATAGATAGATAGC & 48 & 1 & 2 & 3 & 6 & 83 & 0.48 & 2.28 & 2.4 \\
\hline & Total & & & 8 & 14 & 30 & 54 & 85.7 & & 19.3 & \\
\hline & Average & & & & & & & & 0.42 & 2.76 & \\
\hline
\end{tabular}

(ANT) annealing temperature, (NMB) number of monomorphic bands, (NPB) number of polymorphic bands, (TNB) total number of bands, (NUB) number of unique bands unique band (PPB), percentage of polymorphic bands, (PIC) polymorphism information content, (RP) Resolving power, (MI) marker index 
Nosair H.R.
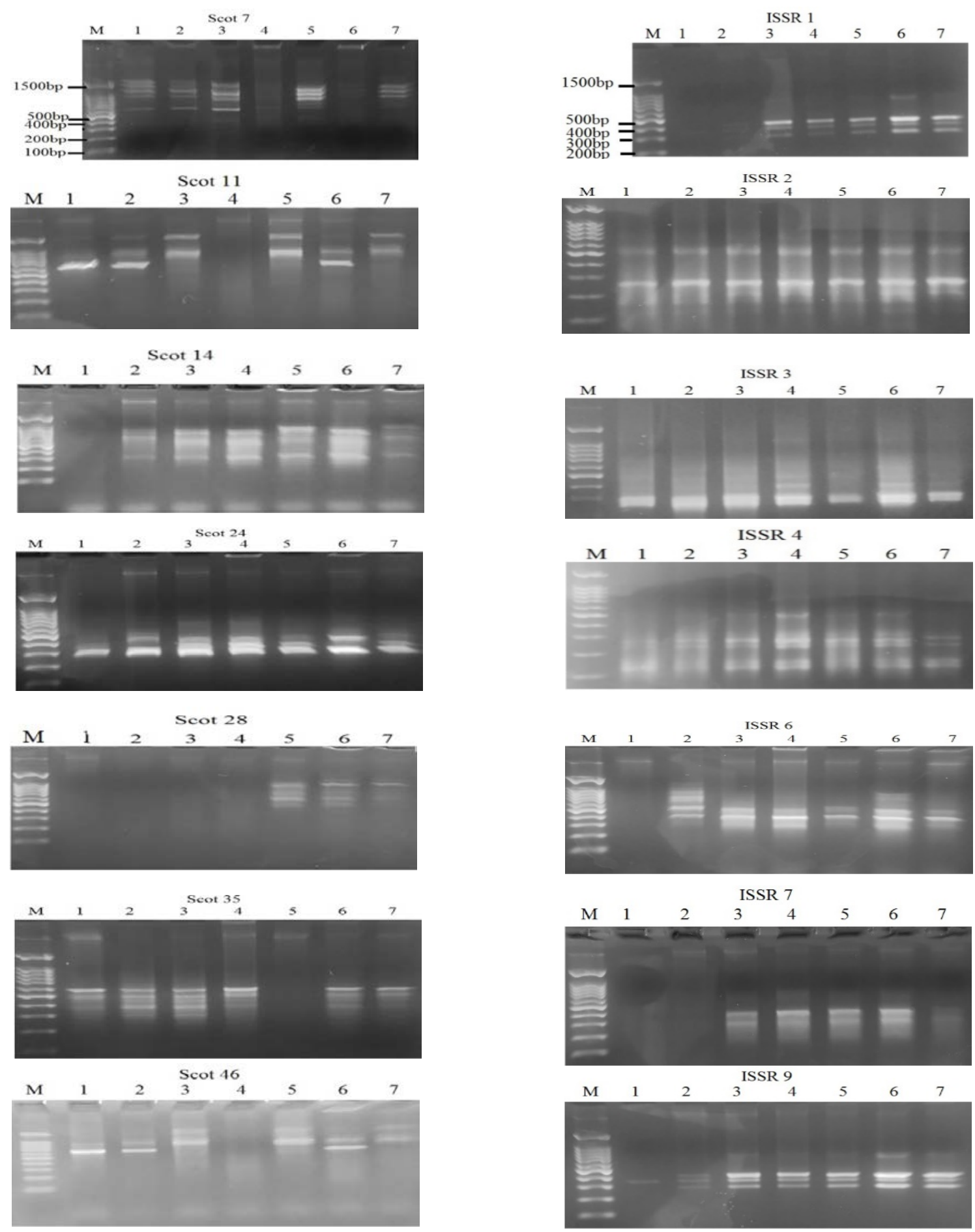

Fig.3 Amplification profiles of seven wheat cultivars DNA samples using 7 Scot primers $\mathrm{M}=$ DNA ladder1= Masr1 2=Swiss2 3=Swiss4 4= Giza7 5= Giza9 6= Giza 10 7= Sakha94

Fig.4 Amplification profiles of seven wheat cultivars DNA samples using 7 ISSR primers $\mathrm{M}=$ DNA ladder1= Masr1 2=Swiss2 3=Swiss4 4= Giza7 5= Giza9 6= Giza 10 7= Sakha94 


\section{Genetic diversity studies on seven Egyptian wheat}

\section{Discussion}

SCoT and ISSR markers are valuable in genetic diversity studies because of their high resolving power (Guo.et al., 2012, Hamidi et al., 2014, Cao et al., 2006 and Sofalian et al., 2009). These markers are efficient and inexpensive analytical methods to evaluate genetic variations for many plants (Xiong et al., 2011, Gorji et al.,2011, Moradkhani et al.,2015 Etminan et al.,2016, PourAboughadareh et al., 2017 and 2018). In the present study, the efficiency of both SCoT and ISSR markers is assessed through parameters such PIC, polymorphism percentage, RP and MI. Parameters such as PIC have been used usually for evaluating the informative potential of ISSR markers in different cultivated genotypes (Gomes et al., 2009 and Tatikonda et al.,2009).Also, the average PIC value per primer of ISSR is equivalent to that found by (Zamanifard et al.,2015, and Hamidi et al.,2014). using SCoT markers in wheat germplasm. In the present study, we compared genetic diversity of wheat cultivars by using SCoT markers of functional domains of well characterized plant genes and ISSR markers (Collard and Mackill., 2009, Abdel-Lateif et al., 2018). Several authors also reported that these marker techniques were able to provide more reliable diversity information (Amirmoradi et al., 2012 and Li et al., 2013 and Poczai et al., 2013) and are useful as tools for studying the genetic diversity of different plant germplasm. At present study showed high genetic diversity among the seven wheat cultivars and this can be useful for utilization in breeding programmed (Tanya et al.,2011). The MI, which can be a common measure of efficiency in discovering polymorphism (Khodadadi et al., 2011), was different in two marker systems (Table 1 \& 2). Our study revealed that RP of SCoT primers is higher than ISSR primers. Genetic corrosion in cultivated wheat provides a good motivation for evaluating genetic diversity among different cultivars (Moradkhani et al., 2012, Abdel-Lateif et al., 2018), as well as determines the possible for improving efficiency of plant materials which eventually may result in improved food production (ElAssal and Gaber, 2012).

\section{Conclusion}

Information about the degree and distribution of genetic variation and relationships among breeding materials has a significant effect on crop improvement. In the present study, SCoT marker, like ISSR marker, was an efficient technique to estimate the genetic variation. Additionally, the large polymorphic fragment percentage, PIC, RP\&MI indicate the power of SCoT marker in fingerprinting and diversity analyses. Also, our results revealed a high genetic variation among tested cultivars, which can be used in wheat breeding program and development of new cultivars.

\section{Acknowledgment}

I would like to thank Prof. Dr. Mohamed Mohamadein Mokhtar professor of microbiology and molecular biology, The Regional Center for Mycology and Biotechnology, Al-Azhar University for his valuable support during this study.

\section{References:}

Abdel-Lateif, K. and Hewedy, O. (1018). Genetic diversity among Egyptian wheat cultivars using scot and issr markers. SABRAO J. of Breeding and Genetics 50 (1) 36-45.

Abdel-Razek, S. (2013). Grain Import Jitters. Al-Ahram Weekly.Cairo,Al-Ahram.

Abdel-Mohsen, A., AboHegazy, S. R. and Moemen, H. (2012). Genotypic and phenotypic interrelationships among yield and yield components in Egyption bread wheat genotypes. Journal of Plant Breeding and Crop Science 4(1):9-16. 
Al-Kordy, M., Shokry, A., Al-Hejin, A., Al-Ahmadi, A., Edris, S., Ramadan, A., Gadalla, N., El-Domyati, F. and Bahieldin, A. (2013). Detection of wheat (Triticum aestivum) cultivars with contrasting performance under abiotic stresses. Life Science Journal. 2(10):2746-2756.

Amirmoradi, B., Talebi, R., and Karami, E. (2012). Comparison of genetic variation and differentiation among annual Cicer species using start codon targeted (SCoT) polymorphism, DAMD-PCR, and ISSR markers. Plant Syst. Evol. 298:1679-1688.

Anderson, J., Churchill, G., Autrique, J, Tanksley, S. and Sorrells, M. (1993). Optimizing parental selection for genetic linkage maps. Genome.;36:181-186.

Awika, J. (2011). Major Cereal Grains Production and Use around the World. In Advances in Cereal Science Implication to Food Processing and Health Promotion, Awika, J.M., Piironen, V., Beans, S., Ed. American Chemical Society,1089: 1-13.

Biswas, M., Xu Q, and Deng, X. (2014). Utility of RAPD, ISSR, IRAP and REMAP markers for the genetic analysis of Citrus spp. Sci Hortic. 124:254-261.

Bornet, B, Branchar, d. (2001). Non anchored. Inter simple sequence repeat (ISSR) markers: reproducible and specific tools for genome fingerprinting. Plant MolBiolRep. 19:209-215.

Cabo, S, Ferreira, L, Carvalho, A, Martins-Lopes, P, Martın, A. and LimaBrito, J. (2014). Potential of start codon targeted (SCOT) markers for DNA fingerprinting of newly synthesized tritordeums and their respective parents. J Appl Genet. 55:307-312

Cao, P., Yao Q., Ding, B., Zing, H., Zeng, H., Zhong, Y. Fu, C. and Jin X. (2006). Genetic diversity of Sinojackia dolichocarpa (Styracaceae), a species endangered and endemic to China, detected by inter-simple sequence repeat (ISSR). Biochem Syst Ecol. 34:231-239.
Chen, L., Zhao, L., Bai, Y., Hu, R. and Si, J. (2009). Genetic relationship analysis of different provenances of Leonurus japonicus by ISSR marker. Zhongguo Zhong Yao Za Zhi 34:1343-1345.

Collard, B. and Mackill, D. (2009). Start codon targeted (SCoT) polymorphism: a simple, novel DNA marker technique for generating gene-targeted markers in plants. Plant. Mol. Biol. Rep. 27: 86-93.

El-Assal, S, Gaber, A. (2012). Discrimination capacity of RAPD, ISSR AND SSR markers and their effectiveness in establishing genetic relationship and diversity among Egyptian and Saudi wheat cultivars. Am J Appl Sci. 9:724-735.

Etminan, A, Pour-Aboughadareh, A, Mohammadi, R,Ahmadi-Rad, A.,Noori A., Mahdavian Z. and Moradi Z. (2016). Applicability of start codon targeted (SCoT) and inter-simple sequence repeat (ISSR) markers for genetic diversity analysis in durum wheat genotypes. Biotechnol Equip. 30:1075-1081.

FAO (2002). World agriculture toward 2015/2030.

ftp://ftp.fao.org/docrep/fao/004/y3557e/y3 557epdf

FAO (2009). http://faostat.fao.org/site/DesktopDefault. aspx?PageID $=567$

Gomes, S., Martins-Lopes, P., Lopes, J. and Pinto, H. (2009). Assessing genetic diversity in Olea europaea L. using ISSR and SSR markers. Plant Mol Biol Rep.; 27:365373.

Gorji, A., Poczai, P, Polgar, $Z$ and Taller, J. (2011). Efficiency of arbitrarily amplified dominant markers (SCoT, ISSR and RAPD) for diagnostic fingerprinting in tetraploid potato. Am Potato J. 88:226-237.

Guo, D, Zhang, J and Liu, C. (2012). Genetic diversity in some grape varieties revealed by SCoT analyses. Mol Biol Rep. 39:5307-5313 
Hamidi, H., Talebi, R. and Keshavarzi, F. (2014). Comparative efficiency of functional gene-based markers, start codon targeted polymorphism (SCoT) and conserved DNAderived polymorphism (CDDP) with ISSR markers for diagnostic fingerprinting in wheat (Triticum aestivum L.). Cereal Res Commun. 42(4):558-567.

Joshi, C., Zhou, H., Huang, X. and Chiang, V. (1997). Context sequences of translation initiation codon in plants. Plant Mol Biol 35:993-1001.

Khodadadi, M., Fotokian, M. and Miransari, M. (2011). Genetic diversity of wheat (Triticum aestivum L.) genotypes based on cluster and principal component analyses for breeding strategies. Aust J Crop Sci. 5:17-24.

Li, T., Guo, J., Li, Y., Ning, H., Sun, X. and Zheng, C. (2013). Genetic diversity assessment of chrysanthemum germplasm using conserved DNA-derived polymorphism markers. Sci. Hortic. 162: 271- 277.

Mardi, M., Naghavi, M., Pirseyedi, S., Kazemi, M., Rashed, S., Ahkami, A., Omidbakhsh, M., Alavi, N., Salehi, P. and Katsiotis, A. (2011). Comparative assessment of SSAP, AFLP and SSR markers for evaluation of genetic diversity of durum wheat (Triticum turgidum L. var. durum). J Agr Sci Tech. 13:905-920.

Milbourne, D., Meyer R., Bradshaw J., Baird E., Bonar N., Provan J., Powell W.and Waugh R. (1997). Comparison of PCR-based marker system for the analysis of genetic relationships in cultivated potato. Mol Breed 3:127-136

Moradkhani, H., Pour-Aboughadareh, A., Mehrabi, A., and Etminan, A. (2012). Evaluation of genetic relationships of Triticum-Aegilops species possessing D genome in different ploidy levels using microsatellites. Int J Agri Crop Sci. 23:17461751.
Moradkhani, H., Mehrabi, A., Etminan, A., and Pour-Aboughadareh, A. (2015). Molecular diversity and phylogeny of Triticum-Aegilops species possessing D genome revealed by SSR and ISSR markers. Plant Breed Seed Sci. 71:82-95.

Poczai, P., Varga, I., Laos, M., Cseh, A., Bell, N., Valkonen, J.and Hyvönen, J. (2013). Advances in plant gene-targeted and functional markers: a review. Plant. Methods 9: 6

Pour-Aboughadareh, A., Ahmadi, J, Mehrabi, A., Etminan, A. and Moghaddam,M. (2017). Assessment of genetic diversity among Iranian Triticum germplasm using agro-morphological traits and start codon targeted (SCoT)markers. Cereal ResCommun. 45:574-586.

Pour-Aboughadareh, A, Ahmadi, J, Mehrab,i A.Etminan, A. and Moghaddam, M. (2017). Insight into the genetic variability analysis and relationships among some Aegilops and Triticum species, as genome progenitors of bread wheat, using SCoT markers. Plant Biosyst. Forthcoming 2018. DOI:10.1080/ 11263504.320311.

Prevost, A. and Wilkinson, M. (1999). A new system of comparing PCR primers applied to ISSR fingerprinting of potato cultivars. Theor Appl Genetic. 98:107-112.

Sawant, S., Singh, P., Gupta, S., Madnala, R. and Tuli R. (1999). Conserved nucleotide sequences in highly expressed genes in plants. J Genet. 78:123-131

Smale, M., Reynolds, M., Warburton, M., Skovmand, B., Trethowan, R., Singh, R., Ortiz-Monasterio, I. and Crossa, J. (2002). Dimensions of diversity in modern spring bread wheat in developing countries from 1965. Crop. Sci. 42: 1766-1779.

Sofalian, O, Chaparzadeh, N, and Dolati, M. (2009). Genetic diversity in spring wheat landraces from northwest of Iran assessed by ISSR markers. Not Bot Horti Agrobot Cluj Napoca. 37:252-256. 
Soleimani, V., Baum, B. and Johnson, D. (2002). AFLP and pedigree-based genetic diversity estimates in modern cultivars of durum wheat (Triticum turgidum L. subsp. durum (Desf.) Husn.). Theor. Appl. Genet. 104: 350-357

Talebi, R., Fayyaz, F. and Karami, M. (2012). Morphometric and amplified fragment length polymorphism marker analysis in some landrace wheat (Triticum aestivum $L$.) genotypes collected from northwest of Iran. Environ. Exp. Biol. 10: 49-56. Tanya, P., Taeprayoon, P. Hadkam, Y. and Srinives, P. (2011). Genetic diversity among Jatropha and Jatropha-related species based on ISSR markers. Plant. Mol. Biol. Rep. 29: 252-264

Tatikonda, L, Wani, S., Kannan, S. and Beerelli, N. (2009). AFLP-based molecular characterization of an elite germplasm collection of Jatrophacurcas L. a biofuel plant. Plant Sci. 176:505- 513

Varshney, R, Chabane, K, Hendre, P, Aggarwal, R. and Graner, A. (2007). Comparative assessment of EST-SSR, EST-
SNP and AFLP markers for evaluation of genetic diversity and conservation of genetic resources using wild, cultivated and elite barleys. Plant Sci. 173:638-649.

Wright, B. and Cafiero, C. (2010). Missing Food: The case of postharvest grain losses in Sub-Saharan Africa. The World Bank, Washington DC, USA. Pp 115.

Xiong, F, Zhong, R, Han, Z, Jiang, J., He, L., Zhuang, W. and Tang R. (2011). Start codon targeted polymorphism for evaluation of functional genetic variation and relationships in cultivated peanut (Arachis hypogaea L.) varieties. Mol Biol Rep. 38:3487-3494

Yu, K. and Pauls, K. (2008). Identification of a RAPD marker associated with somatic embryogenesis in alfalfa. Plant Mol. Biol. 22, 269-277.

Zamanianfard, Z, Alireza, Etminan, A, Mohammadi, R and Shooshtari, L. (2015). Evaluation of molecular diversity of durum wheat genotypes using ISSR markers. Biol Forum.; 7:214-218. 